\title{
Developing mobile self-tracking for chronic disease prevention: Why listening to users matters?
}

\author{
Vasileios Nittas ${ }^{1}$
}

Received: 8 May 2019/Revised: 24 February 2020 / Accepted: 1 March 2020/ Published online: 23 March 2020

(c) Swiss School of Public Health (SSPH+) 2020

Smartphones and their health applications (apps) are an integral part of our daily lives, silently tracking our bodily functions and behaviors and changing the ways we perceive ourselves and our environments (Platt et al. 2016). If used correctly, mobile self-tracking technology can help prevent disease without much burden to healthcare systems that operate under resource and human power constraints (Mehl et al. 2014). Despite remaining challenges, like ensuring data quality and privacy, we expect self-tracking data to be increasingly integrated into electronic medical records and used to personalize and improve prevention (Buchwald et al. 2017; Vydra et al. 2015).

Targeted use of mobile health (mHealth) technologies is advocated by the World Health Organization (WHO), as they may help address the growing burden of chronic disease (WHO 2017). MHealth enables the continuous tracking of health and well-being parameters (hereby referred to as mobile self-tracking) and may facilitate disease prevention by giving users access to better, faster and personalized health information (WHO 2017). Despite its potential, the use of mobile self-tracking is usually short-term, as many users rapidly lose interest, abandon the devices and either inactivate or delete the tracking applications (WHO 2017; Buchwald et al. 2018). For mobile self-tracking technologies to serve their purpose of facilitating prevention and collecting data over the long-term, researchers, policymakers and public health professionals need to understand and thoroughly address this trend of quick disengagement (WHO 2017; Buchwald et al. 2018).

This Editorial is part of the series "Young Researcher Editorial", a training project of the Swiss School of Public Health.

\footnotetext{
Vasileios Nittas

vasileios.nittas@uzh.ch

1 Epidemiology, Biostatistics and Prevention Institute, University of Zurich, Hirschengraben 84, 8001 Zurich, Switzerland
}

Here, as part of the solution, I argue that we need to carefully listen to users, especially during the early development of mobile self-tracking technology; an early user focus through listening is key to ensuring their longterm success and impact.

Acceptance and use of mobile self-tracking depends on multiple factors (e.g., personal drive, knowledge, awareness, digital affinity, beliefs, preferences, attitudes, selfefficacy, trust, needs and expectations) that can either inhibit or facilitate uptake (Buchwald et al. 2018; Hardiker and Grant 2011). Results of recent studies on mobile selftracking technology development underline the benefits of an early user focus. For example, experts and users contributed to developing a web and mobile-based foot exercise tool to prevent diabetes-related complications, and the process identified several functions that would motivate users and keep them engaged. Personalizing exercises, as well as including simple and intuitive content and weekly motivational reminders, were a few examples of functions that users valued (Ferreira et al. 2019). Similarly, a mobile electronic heart diary, designed to prevent the progress of heart failure by monitoring weight and blood pressure, retained an early user focus by including elements tailored to the target population's age group. Since heart failure is most common among the elderly, the tool included social functions like allowing users to ask relatives and friends to create challenges made up of goals (e.g., self-tracking for a certain time period) and rewards (e.g., going out for dinner if goal achieved). The study included the opinions of elderly users, who described the function as motivating and engaging, highlighting its potential to make the app more acceptable for long-term use (Arulnathan et al. 2019).

Early user focus is in line with the concept of a personcentered approach, which is part of the Principles of Digital Development and is based on idea that users should be central partners in designing and developing technology (digitalprinciples.org). Development processes that are not person-centered may not meet user needs and thus inhibit long-term use. A randomized controlled trial of an mHealth 
program included user interviews in its effort to build an app and physical activity tracer to prevent prediabetes progression. This process determined which functions users liked and disliked and identified that users thought daily app use was redundant because their health behavior (e.g., exercise) does not fluctuate significantly over the shortterm. Without this listening process, the developers of this program could not have adjusted the device to meet user needs (Griauzde et al. 2019). Consequentially, failing to meet user needs likely predicts a short and ineffective use.

If mobile self-tracking technologies are to achieve longterm use, they need to inspire trust, protect privacy and avoid conveying a feeling of constant surveillance (Leibenger et al. 2016). This can only be achieved in cooperation with users, as in the case of the diabetes-targeted foot exercise tool, where user input revealed that trust building required clear and transparent information on data safety (Ferreira et al. 2019). Finally, if we want mobile selftracking technology to help us prevent disease, technology developers must include user voices and their perspectives from the very first development stages and solicit their input throughout the process, aiming for acceptance engagement motivation. Technology implementers must be fully informed and willing to acknowledge and address these perspectives.

Acknowledgements I would like to thank PD Dr. Margot Mütsch and Prof. Dr. Milo Puhan for critically reviewing this editorial.

\section{Compliance with ethical standards}

Conflict of interest The authors declare that they have no conflict of interest.

\section{References}

Arulnathan A, Vaaheesan S, Denecke K (2019) A mobile application for self-monitoring for patients with heart failure. Stud Health Technol Inform 259:113-116

Buchwald A, Letner A, Urbach N, von Entreß-Fürsteneck M (2017) Towards explaining the willingness to disclose personal self- tracking data to service providers. In: Proceedings of the 25th European conference on information systems (ECIS), Guimarães, Portugal, June 5-10, 2017, pp 3071-3081. http://aisel.aisnet. org/ecis2017_rip/55

Buchwald A, Letner A, Urbach N, von Entreß-Fürsteneck M (2018) Insights into personal ICT use: understanding continuance and discontinuance of wearable self-tracking devices. In: Proceedings of the 26th European conference on information systems. https://pdfs.semanticscholar.org/5d98/f97ab2680d83ee597aae23 f446de00bc075a.pdf

Ferreira JS, Sacco IC, Siqueira AA, Almeida MH, Sartor CD (2019) Rehabilitation technology for self-care: customised foot and ankle exercise software for people with diabetes. PLoS ONE 14(6):e0218560

Griauzde D, Kullgren JT, Liestenfeltz B, Ansari T, Johnson EH, Fedewa A, Saslow LR, Richardson C, Heisler M (2019) A mobile phone-based program to promote healthy behaviors among adults with prediabetes who declined participation in free diabetes prevention programs: mixed-methods pilot randomized controlled trial. JMIR mHealth uHealth 7(1):e11267

Hardiker NR, Grant MJ (2011) Factors that influence public engagement with eHealth: a literature review. Int J Med Inform 80(1):1-12. https://doi.org/10.1016/j.ijmedinf.2010.10.017

Leibenger D, Möllers F, Petrlic A, Petrlic R, Sorge C (2016) Privacy challenges in the quantified self movement-an EU perspective. In: Proceedings on privacy enhancing technologies, Darmstadt, Germany, July 19-22, pp 315-334

Mehl G, Vasudevan LSE, Gonsalves L, Berg M, Seimon T et al (2014) Harnessing mHealth in low-resource settings to overcome health system constraints and achieve universal access to healthcare. Behavioral healthcare and technology: using science-based innovations to transform practice. Oxford University Press, Oxford

Platt A, Outlay C, Sarkar P, Karnes S (2016) Evaluating user needs in wellness apps. Int $\mathbf{J}$ Hum Comput Interact 32(2):119-131. https://doi.org/10.1080/10447318.2015.1099803

Principles for Digital Development. https://digitalprinciples.org. Accessed 16 May 2019

Vydra TP, Cuaresma E, Kretovics M, Bose-Brill S (2015) Diffusion and use of tethered personal health records in primary care. Perspect Health Inf Manag 12:1c

World Health Organization (WHO) (2017) mHealth use of appropriate technologies for public health. Report by the Directorate General. https://apps.who.int/iris/bitstream/handle/10665/ 274134/B142_20-en.pdf?sequence $=1$ \&isAllowed $=y$. Accessed 2 May 2019

Publisher's Note Springer Nature remains neutral with regard to jurisdictional claims in published maps and institutional affiliations. 